\title{
Association between Blood Lipids and Types of Stroke
}

\author{
Sergio González García, MS, Otman Fernández Concepción, MD, MS, Rebeca Fernández Carriera, BS, \\ Caridad Menéndez Saínz, MS, Julia Maza, MD, PhD, Alina González-Quevedo Monteagudo, MD, DrSc, \\ Miguel Ángel Buergo Zuaznábar, MD
}

\begin{abstract}
Introduction Many studies to date on the link between blood lipid levels and cerebrovascular disease have been hampered by conceptual and methodological limitations, especially failure to separate different types of stroke.

Objective Determine the relationship between serum lipid levels and the occurrence of different types of stroke.

Methods Two case and control studies were undertaken. The first consisted of three groups: subjects with cerebral infarction $(\mathrm{Cl})$, subjects with cerebral hemorrhage $(\mathrm{CH})$ and a control group of healthy individuals with no history of cerebrovascular disease. The second study included three groups: those with atheromatous $\mathrm{Cl}$, those with $\mathrm{Cl}$ of other etiology, and the healthy control group. The influence of variables such as age, sex, and presence of risk factors was also assessed.
\end{abstract}

Results $\mathrm{Cl}$ patients were found to have higher total cholesterol levels $(p<0.01)$, low-density lipoprotein $(L D L)$ cholesterol $(p<0.01)$, and

\section{INTRODUCTION}

The scientific community recognizes the association between blood lipids levels and risk of cardiovascular disease.[1] Strong association has been found between high levels of serum cholesterol - especially of low-density lipoprotein (LDL) cholesterol - and the development of atherosclerosis, while elevated levels of high-density lipoprotein (HDL) cholesterol seem to play a protective role.[1] However, evidence linking blood lipids to cerebrovascular diseases has failed to put an end to a long-standing controversy: Is there a correlation between blood lipid levels and occurrence of stroke? In our opinion, a conclusive answer has not been found, since many studies to date have been hampered by conceptual and methodological limitations.

These limitations can be summarized as follows: (1) stroke has been studied as a single entity, without distinguishing between cerebral infarction $(\mathrm{Cl})$ and cerebral hemorrhage $(\mathrm{CH})$; (2) strokes of ischemic origin have been studied without separate consideration of each etiopathogenic subtype; (3) populations have been studied that were selected according to other criteria - such as those with high cardiovascular risk - not necessarily representative of normal stroke behavior; and (4) blood lipid levels have been considered a nominal, rather than a continuous, variable using arbitrary lipid level classification categories.

A good example of the above is the well-known Prospective Studies Collaboration, a meta-analysis of 450,000 persons in 45 prospective cohorts studied over an average of 16 years. These studies did not find an association between total cholesterol levels and stroke.[2] Cerebrovascular accidents (CVA) were not analyzed by type of stroke (ischemic or hemorrhagic), and in par- triglycerides $(p<0.01)$ than those in the control group. $\mathrm{CH}$ patients had lower total cholesterol levels $(p<0.05)$, and higher triglycerides levels $(p<0.05)$ than the control group. The second study revealed a link between blood lipid levels and $\mathrm{Cl}$ only in cases of atheromatous stroke. This association was prevalent in women, and was independent of other risk factors.

Conclusions The type of stroke (ischemic or hemorrhagic) and the etiopathogenic subtype of $\mathrm{Cl}$ must be considered when studying association between blood lipids and occurrence of stroke. Elevated levels of total cholesterol, LDL and triglycerides are associated with occurrence of atheromatous $\mathrm{Cl}$, while low total cholesterol levels and high triglycerides levels are associated with the $\mathrm{CH}$ occurrence.

Keywords: cholesterol, HDL, LDL, triglycerides, cerebral hemorrhage, cerebral infarction, atherosclerosis, vascular diseases, cerebrovascular disorders, stroke, cerebrovascular accident, CVA, ischemia, hyperlipidemias

ticular, atherothrombotic $\mathrm{Cl}$ was very poorly represented. Many of the cohorts were initially selected to study incidence of coronary heart disease (CHD) and thus consisted of middle-aged individuals at risk of myocardial infarction. That is, the primary aim of the study was not to explore occurrence of stroke.

Results change dramatically when ischemic and hemorrhagic strokes are assessed separately. For example, the Multiple Risk Factor Intervention Trial (MRFIT) demonstrated that mortality risk from non-hemorrhagic stroke increased proportionately with serum cholesterol levels in 351,000 men aged 35-57 years. Conversely, negative association was found between hemorrhagic stroke and cholesterol levels below $200 \mathrm{mg} / \mathrm{dl}$ : the lower the blood cholesterol level the greater risk of hemorrhagic stroke.[3] This suggests a U-shaped correlation between blood cholesterol levels and risk of stroke. Combining both types of stroke in a single study, as in the cohort examined for the Prospective Studies Collaboration, masks correlation between blood cholesterol levels and risk of stroke.[2]

The advent of HMCoA reductase inhibitors (statins), has contributed new evidence supporting association of total cholesterol and LDL levels with risk of $\mathrm{Cl}$, with no modification of risk for hemorrhagic stroke. A meta-analysis of nine clinical trials of statins[4] showed that these drugs reduced $\mathrm{Cl}$ risk in patients with a history of CHD. Furthermore, the Stroke Prevention by Aggressive Reduction in Cholesterol Levels (SPARCL) study found that statins use significantly reduced relapse risk in patients who had suffered $\mathrm{Cl}$ or a transient ischemic attack (TIA).[5] A possible limitation of such trials' ability to demonstrate association between blood lipids and $\mathrm{Cl}$ is that statins apparently have a favorable effect on

This article has been corrected. The specific correction appears at the end of this document. 
atheromatous lesions, unrelated to reduction in total cholesterol and LDL levels.[6]

The objectives of this study are to: (1) determine differences between blood lipid levels in subjects with one of two types of stroke (ischemic or hemorrhagic), compared to those of a control group; and (2) determine differences in blood lipids between etiopathogenic subtypes of $\mathrm{Cl}$.

\section{METHODS}

A case and control study was conducted to determine differences in serum lipid levels among individuals suffering different types of stroke.

Participants included patients in the acute phase of stroke (within 24 to 72 hours of onset) admitted to Havana's Institute of Neurology and Neurosurgery from August 2002 to January 2004. Stroke diagnosis was based on clinical examination and a cranial computer tomography (CT) scan.

For our first objective, subjects were divided into 3 groups: cerebral infarction $(\mathrm{Cl})$ patients, cerebral hemorrhage $(\mathrm{CH})$ patients, and a control group. For our second objective, subjects were divided into 3 groups: patients with atheromatous cerebral infarction ( $\mathrm{ACl}$ ) (including atherothrombotic and lacunar infarction), patients with non-atheromatous cerebral infarction (NACl) (those with cardioembolic $\mathrm{Cl}$ and those with $\mathrm{Cl}$ of unknown origin), and the healthy control group. Individuals in the control group, those with no history of cerebrovascular disease, were randomly selected from the geographic health areas served by the Moncada and Rampa community polyclinics in the Plaza de la Revolución municipality of Havana. Relevant characteristics of patients and control group are presented in Table 1.

The study was approved by the Institute of Neurology and Neurosurgery's Ethics Committee. All potential participants were given the necessary information about the study, and each participant provided written informed consent.

Dependent variables Serum lipid levels: LDL, HDL and total cholesterol (TC); and triglycerides (TG). All were considered continuous variables. Independent variables Study group as a nominal variable. For analysis related to the first objective, groups were: cerebral infarction $(\mathrm{Cl})$, cerebral hemorrhage $(\mathrm{CH})$, and control group. For analysis related to the second objective, groups were: atheromatous cerebral infarction $(\mathrm{ACl})$,

Table 1: Baseline Characteristics of Patients and Controls

\begin{tabular}{|c|c|c|c|c|c|}
\hline \multicolumn{2}{|l|}{ Variable } & $\begin{array}{l}\mathrm{ACl} \\
(n=85)\end{array}$ & $\begin{array}{l}\mathrm{NACl} \\
(n=48)\end{array}$ & $\begin{array}{l}\mathrm{CH} \\
(n=31)\end{array}$ & $\begin{array}{l}\text { Control } \\
(n=131)\end{array}$ \\
\hline \multicolumn{2}{|l|}{ Age } & $61.3 \pm 11.6$ & $58.5 \pm 10.4$ & $52 \pm 9.7$ & $60 \pm 12.3$ \\
\hline \multirow[t]{2}{*}{ Sex } & M & 39 & 19 & 15 & 77 \\
\hline & $\mathrm{F}$ & 46 & 29 & 16 & 54 \\
\hline \multicolumn{2}{|c|}{ Hypertension } & 68 & 32 & 18 & 48 \\
\hline \multicolumn{2}{|c|}{ Diabetes Mellitus } & 54 & 22 & 11 & 55 \\
\hline \multicolumn{2}{|c|}{$\begin{array}{l}\text { History of Vascular } \\
\text { Disease }\end{array}$} & 56 & 31 & 18 & 41 \\
\hline \multicolumn{2}{|c|}{ Hyperlipidemia } & 61 & 15 & 13 & 79 \\
\hline
\end{tabular}

$n=$ total number of individuals in each group.
Table 2: Etiology of Cerebral Infarction by Ibero-American Society of Cerebrovascular Diseases Classifications

\begin{tabular}{|c|c|}
\hline \multirow[t]{3}{*}{$\begin{array}{l}\text { Atherothrombotic } \\
\text { Infarction (large } \\
\text { vessel } \\
\text { atherosclerosis) }\end{array}$} & $\begin{array}{l}\text { Usually medium-sized or large ischemic le- } \\
\text { sion, located in the cortical or subcortical area, } \\
\text { caused by carotidal or vertebrobasilar stenosis. } \\
\text { One of the following two criteria is met: }\end{array}$ \\
\hline & $\begin{array}{l}\text { - Atherosclerosis with stenosis: stenosis of } 50 \% \\
\text { or more of the luminal diameter, or occlusion } \\
\text { of extracranial carotid artery or of large intrac- } \\
\text { ranial carotid artery in the absence of another } \\
\text { etiology. }\end{array}$ \\
\hline & $\begin{array}{l}\text { - Atherosclerosis without stenosis: presence } \\
\text { of atheromatous plaques or of stenosis (less } \\
\text { than } 50 \% \text { ) in the abovementioned arteries, in } \\
\text { the absence of another possible etiology, plus } \\
\text { at least two of the following cerebrovascular } \\
\text { risk factors: age }>50 \text { years, hypertension, } \\
\text { diabetes mellitus, tobacco use or hypercholes- } \\
\text { terolemia. }\end{array}$ \\
\hline $\begin{array}{l}\text { Small Vessel } \\
\text { Arterial Occlusive } \\
\text { Disease } \\
\text { (Lacunar Infarction) }\end{array}$ & $\begin{array}{l}\text { Small ischemic lesion ( }<1.5 \mathrm{~cm} \text { diameter) } \\
\text { in the area supplied by a perforating artery, } \\
\text { which usually causes lacunar syndrome (pure } \\
\text { motor hemiparesis, pure sensory syndrome, } \\
\text { sensorimotor syndrome, ataxic hemiparesis } \\
\text { and dysarthria/clumsy hand), in the absence of } \\
\text { another etiology. }\end{array}$ \\
\hline $\begin{array}{l}\text { Cardioembolic } \\
\text { Infarction }\end{array}$ & $\begin{array}{l}\text { Usually medium-sized or large ischemic lesion, } \\
\text { normally located in the cortical area, accompa- } \\
\text { nied by presence of high-risk embolic cardiopa- } \\
\text { thy, in the absence of another etiology. }\end{array}$ \\
\hline $\begin{array}{l}\text { Stroke of Unknown } \\
\text { Origin }\end{array}$ & $\begin{array}{l}\text { Medium-sized or large ischemic lesion, located } \\
\text { in cortical or subcortical area, in area supplied } \\
\text { by the carotid or vertebrobasilar arteries, when, } \\
\text { following an in-depth diagnostic study, the } \\
\text { following types of stroke have been ruled out: } \\
\text { atherothrombotic, cardioembolic, lacunar, of } \\
\text { unusual origin, or when more than one possible } \\
\text { etiologies exist. }\end{array}$ \\
\hline
\end{tabular}

non-atheromatous cerebral infarction (NACI), and control group.

Intermediate variables Age (continuous variable); sex (nominal, dichotomous variable); and presence of other risk factors, including hypertension (HTN), diabetes mellitus (DM) or coronary heart disease (CHD). These are all nominal, dichotomous variables with only one value: "yes" or "no".

To determine serum lipids levels, blood samples were taken following a 12-hour fast, and then processed. Serum was stored at $-20^{\circ} \mathrm{C}$ for no longer than 20 days. TC was determined by enzyme assay (ELISA), CHOD-PAP method, and triglycerides levels by GPO-PAP method. [7] HDL was analyzed following a selective precipitation in the presence of phosphotungstic acid and magnesium. LDL levels were obtained through precipitation with heparin.[8] All reagents used were manufactured by Merck (Germany). Normal values for lipid variables used as reference were: total cholesterol: $3.5-6.1 \mathrm{mmol} / \mathrm{L}$; triglycerides: 0.2-1.7 mmol/L; LDL: 2.7-3.4 mmol/L and HDL: $>1.0 \mathrm{mmol} / \mathrm{L}$.

The Ibero-American Society of Cerebrovascular Disease's criteria for classification of cerebrovascular diseases were used for etiopathogenesis, as shown in Table 2.[9] 
A simple-classification variance analysis (ANOVA) was used to compare lipid levels among the groups studied, and differences among mean values obtained were defined by Tukey test.[10] To determine the effect of intermediate variables on the association between lipid levels and study groups, a multivariate ANOVAMANOVA test was used. The t-Student mean-difference test was used to determine differences among dichotomous variables.[10] In all cases, a 95\% confidence level was used.

A statistical strength of $80 \%$ and a confidence level of $95 \%$ were considered when calculating the number of patients in the sample.

Figure 1: Serum Lipids Levels of Three Groups Studied

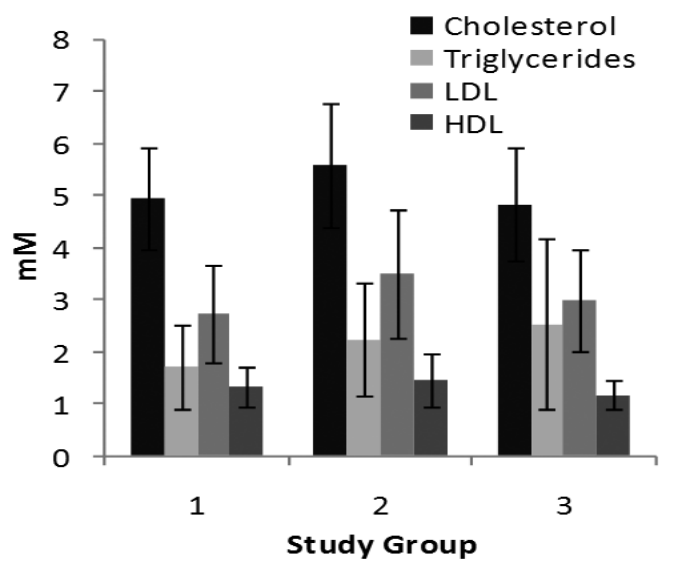

Study Groups: (1) Control, (2) Cerebral Infarction, (3) Cerebral Hemorrhage Results of the ANOVA Test:

Cholesterol: $\quad F=12.06 ; p=0.000$

Triglycerides: $\quad F=8.07 ; p=0.000$

HDL: $\quad F=1.02 ; p=0.36$

LDL: $\quad F=14.72 ; p=0.000$

\section{RESULTS}

Figure 1 shows that $\mathrm{Cl}$ patients had higher mean levels of total cholesterol $(p<0.01)$, LDL $(p<0.01)$, and triglycerides $(p<0.01)$ than the control group - a statistically significant difference.

Conversely, $\mathrm{CH}$ patients had significantly lower levels of total cholesterol $(p<0.05)$ and higher levels of triglycerides $(p<0.001)$ than the control group. $\mathrm{Cl}$ patients were found to have higher levels of total cholesterol and LDL $(p<0.05)$ and lower levels of triglycerides $(p<0.05)$ than those with $\mathrm{CH}$.

Figure 2 shows mean serum lipids levels in the $\mathrm{ACl}, \mathrm{NACl}$ and control groups. When mean levels were compared by variance analysis, F-values and significance levels were noteworthy. As can be observed, individuals with $\mathrm{ACl}$ exhibited statistically significant higher levels of TC and LDL than the other two groups. $\mathrm{TC}$ levels of $\mathrm{NACl}$ patients did not differ significantly from those of the control group, while differences in LDL levels between the two groups were less significant.

Triglycerides levels were highest in the $\mathrm{ACl}$ group, showing highly significant differences with the control group and less significant differences with the NACI group. The highest HDL levels were found in the control group; but differences among the other groups were not statistically significant.
Figure 2: Serum Lipids Levels in Cerebral Infarction (Cl) by Etiopathogenesis

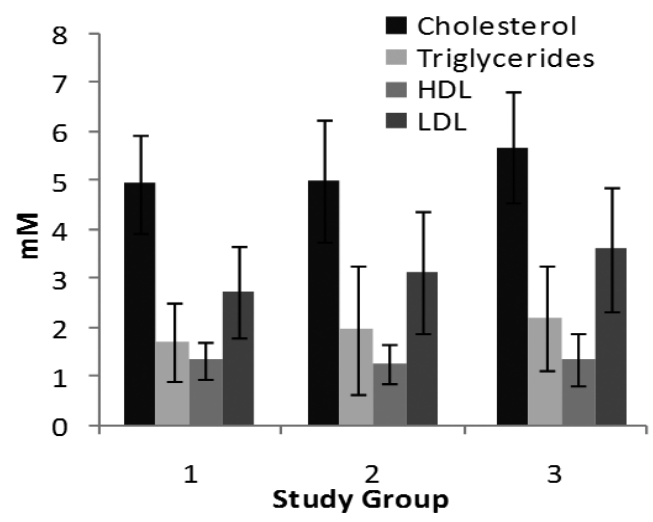

Groups: (1) Control (n=131), (2) NACI ( $n=48),(3) \mathrm{ACl}(n=85)$

Results of the ANOVA Test:

Cholesterol: $\quad F=17.94 ; p=0.000$

Triglycerides: $\quad F=4.87 ; p=0.002$

HDL: $\quad F=3.35 ; p=0.066$

LDL: $\quad F=18.34 ; p=0.000$

Table 3 presents variance analysis results according to two factors: group ( $\mathrm{ACl}, \mathrm{NACl}$ or control) and sex.

These factors were considered for each of the serum lipids variables included in the study. Post-hoc comparison analysis revealed that differences in mean lipids levels between the $\mathrm{ACl}$ group and the other two were only significant in women.

Table 4 presents multivariate analysis assessments of the influence of the study group and additional risk factors (HTM, $\mathrm{DM}$, tobacco use and history of $\mathrm{CHD}$ ) on serum lipids level

Table 3: Comparison of Mean Serum Lipids Levels by Sex and Study Groups, Two-Factor Variance Analysis

\begin{tabular}{lcccc} 
Group & $\begin{array}{c}\text { Total Cholesterol } \\
(\mathrm{mmol} / \mathrm{L})\end{array}$ & $\begin{array}{c}\text { Triglycerides } \\
(\mathrm{mmol} / \mathrm{L})\end{array}$ & $\begin{array}{c}\mathrm{LDL} \\
(\mathrm{mmol} / \mathrm{L})\end{array}$ & $\begin{array}{c}\mathrm{HDL} \\
(\mathrm{mmol} / \mathrm{L})\end{array}$ \\
Male-ACl & 5.54 & 2.19 & 3.47 & 1.16 \\
Male-NACl & 5.10 & 2.34 & 3.35 & 1.01 \\
Male-Control & 5.15 & 1.94 & 2.72 & 1.18 \\
\hline Female-ACl & $5.92 \mathrm{a}$ & $2.26 \mathrm{a}$ & $3.85 \mathrm{a}$ & $1.06 \mathrm{a}$ \\
Female-NACl & $5.07 \mathrm{~b}$ & $1.31 \mathrm{~b}$ & $3.11 \mathrm{~b}$ & $1.18 \mathrm{a}$ \\
Female-Control & $4.86 \mathrm{~b}$ & $1.44 \mathrm{~b}$ & $2.68 \mathrm{~b}$ & $1.28 \mathrm{~b}$
\end{tabular}

Letters $(a, b)$ identify mean values for each of the analytes evaluated: means with same letters indicate no statisically significant difference; means with different letters indicate significant results $(p<0.05)$

Table 4: Impact of Selected Risk Factors on Cholesterol and Triglycerides Serum Levels, Multivariate Analysis

\begin{tabular}{lcccc} 
& \multicolumn{2}{c}{ Cholesterol } & \multicolumn{2}{c}{ Triglycerides } \\
Factor & $F$ & $p$ & $F$ & $p$ \\
\hline Study Group & 7.34 & $0.000^{* *}$ & 1.40 & 0.246 \\
Hypertension & 1.60 & 0.206 & 0.00 & 0.965 \\
Diabetes Mellitus & 0.00 & 0.975 & 1.20 & 0.275 \\
Smoking & 0.27 & 0.603 & 2.72 & 0.100 \\
History of Coronary & 0.09 & 0.768 & 4.13 & $0.043^{*}$ \\
Heart Disease & & & &
\end{tabular}

*In post-hoc analysis, no significant differences were found in the levels of triglycerides in relation with the factors studied (study group and history of coronary heart disease). ${ }^{* *}$ Highly significant 
variation. As can be observed, all variation can be attributed to the study group under consideration.

\section{DISCUSSION}

Concerning the study's first objective: we found that $\mathrm{Cl}$ patients had a more atherogenic serum lipids profile than the healthy control group or $\mathrm{CH}$ patients. The $\mathrm{Cl}$ patients' lipids profile was characterized by higher total cholesterol, LDL, and triglycerides levels than those in the control group; as well as higher total cholesterol and LDL levels, and lower triglycerides levels when compared to the $\mathrm{CH}$ group. $\mathrm{CH}$ patients had lower levels of total cholesterol and higher levels of triglycerides than the control group.

The difference in serum lipids behavior between patients with ischemic and hemorrhagic stroke addresses the controversy surrounding the role of blood lipids levels in risk of cardiovascular accidents (CVA). Many studies conducted thus far have compared a group of CVA patients with the general population, without distinguishing the type of stroke under consideration.

The evidence linking total cholesterol and LDL with $\mathrm{Cl}$ risk is based on three types of studies: case and control studies, longitudinal prospective studies, and clinical trials using $\mathrm{HMCOA}$ reductase inhibitors (statins).

In addition to research published by our team,[11] we have found four case and control studies carried out in China, [7,12-14] which obtained similar results: $\mathrm{Cl}$ patients had significantly higher levels of total cholesterol, LDL, and triglycerides than those in control groups. Furthermore, $\mathrm{CH}$ subjects exhibited significantly lower levels of total cholesterol and LDL.[13] A study conducted in Italy by Denti et al showed an independent association of high levels of LDL and low levels of HDL with risk of cerebral infarction.[15]

A study conducted of 24,342 women with no history of cardiovascular disease, using data from eight US studies included in the Women's Pooling Project, found that high blood cholesterol is a risk factor for mortality from non-hemorrhagic stroke in women aged $<55$ years. [16]

Amarenco et al. carried out a meta-analysis of 70,020 persons who participated in clinical trials on $\mathrm{HMCoA}$ reductase inhibitors (statins), finding a $21 \%$ risk reduction of $\mathrm{Cl}$, with no increased risk of brain hemorrhage.[4] In another more detailed study, the author reported that each $10 \%$ reduction in LDL levels resulted in a $15.6 \%$ annual reduction in risk of stroke.[17] Other clinical trials with statins report that patients at risk of cardiovascular disease and stroke should be treated with this type of medication regardless of sex, race or baseline blood cholesterol levels.[18] In addition to the SPARCL study, earlier research by Sasaki et al - Kyushu Lipid Intervention Study - involving 4,615 men aged 45-74 years followed up for 5 years, found that cholesterol reduction with statins reduced risk of stroke by $70 \%$.[19]

Over the last decade, HDL has also been the subject of research and controversy in scientific literature; a protective effect against ischemic coronary episodes has been suggested.[20] We found no significant differences in HDL among the three groups studied, even when the etiopathogenesis of ischemic stroke was considered.
These findings contradicted some earlier reports such as those from the Israeli Ischemic Heart Study. This 21-year prospective study of 8,586 men concluded that adjusted mortality due to ischemic stroke is 1.3 higher among men with low levels of HDL than in those with higher levels of this cholesterol fraction.[21] Soyama et al, in a 10-year follow-up study of 4,989 individuals aged 35-79 years, found significant association between low HDL levels and increased risk of stroke.[22]

The second aim of our study was to address the other part of the controversy regarding the role of serum lipids levels in cerebrovascular disease. The results obtained for patients with atheromatous $\mathrm{Cl}$ (including atheromatosis of both large and small vessels) were markedly different to those found for the control group. In other words, a separate analysis based on the etiopathogenic subtype showed that atheromatous $\mathrm{Cl}$ patients have a more atherogenic serum lipids profile than patients with $\mathrm{Cl}$ of other origins, the latter exhibiting a serum lipids profile - excluding triglycerides - similar to that of the healthy control group.

Due to its varied etiopathogenesis, $\mathrm{Cl}$ can be considered a syndrome. Hence, risk and associated factors must be considered independently and according to subtype. The vast majority of studies conducted to date have not done so. Although ischemic heart disease is caused almost exclusively by coronary atheromatosis, ischemic cerebral diseases have a wide range of causal factors, of which atheromatosis accounts for only about $30 \%-50 \%$ of cases.[23,24]

In an earlier study of another sample of patients, our team obtained similar results.[25] However, studies separating the different etiological subtypes of $\mathrm{Cl}$ are still rare in the literature. Studies such as the one conducted by Bowman et al, of $296 \mathrm{Cl}$ patients and the same number of controls, found that levels neither of total cholesterol, triglycerides nor HDL were associated with risk of ischemic stroke, although a high total cholesterol/HDL ratio was found to increase risk. In this study, the etiopathogenic subtypes of $\mathrm{Cl}$ were not considered separately.[26]

Significant statistical differences were found between the triglycerides levels in patients in the $\mathrm{NACl}$ group and those in the control group. This coincides with findings reported by Laloux et al, which showed that hypertriglyceridemia is relatively common among patients with $\mathrm{Cl}$ of any origin.[27]

A noteworthy finding in our study was that most of the differences found between both study groups were more prevalent among women (60\%). Although men with $\mathrm{ACl}$ exhibited the highest levels of total cholesterol and LDL, highly statistically significant differences were found only among women, according to two-factor variance analysis used. Differences were especially significant in the case of triglycerides, whose levels were similar among men, but very different among women.

The mean age of participants shows that most were older adults. This means that the women were postmenopausal, lacking protection from estrogen to keep blood lipids levels low.[28] During this period in women's lives, risk of atherosclerosis increases, and one cause may be the marked increase in total cholesterol and LDL, as well as triglycerides levels. This finding requires further 
study beyond the scope of our current research. Furthermore, results published in the literature to date are varied. As stated earlier, two studies have reported that cholesterol was indeed related to ischemic stroke in women.[16,17] In the Women's Pooling Project study, the risk was found to be significantly higher among premenopausal women.[16]

Although our findings indicate that $\mathrm{CH}$ is associated with lower lipids levels, some studies have found that hypercholesterolemia is a protective factor against $\mathrm{CH}$ and that low blood cholesterol increases risk. A five-year prospective study by Okumura et al in Japan followed 38,053 individuals selected from a mass blood lipids screening carried out in 1983, to assess occurrence of stroke from 1988 to 1991.[29]

This study showed that low levels of blood cholesterol was an independent predictor for $\mathrm{CH}$. Another prospective study, by Iribarren et al, of 61,756 individuals enrolled in a health plan in the San Francisco metropolitan area,[30] found an association between low levels of serum cholesterol and $\mathrm{CH}$; however, this study included only men aged $>65$ years.

In a recent article, Amarenco and Steg[31] reviewed 61 prospective observational studies, and concluded that no association exists between total cholesterol and stroke mortality. These authors acknowledged that stroke is a multifactorial disease and that its various causes are not equally associated with blood cholesterol levels. They also stated that if a correlation were to exist between cholesterol levels and risk of stroke, it would be with atherothrombotic $\mathrm{Cl}$. We find an explanation in our study for the lack of association reported by these authors. Stratifying the different types and etiologies of stroke has enabled us to demonstrate that pa- tients with $\mathrm{Cl}$ have higher total cholesterol and LDL levels, and lower triglycerides levels than patients with $\mathrm{CH}$. Furthermore, atheromatous cerebral infarction $(\mathrm{ACl})$ was characterized by an increase in total cholesterol, LDL, and triglycerides levels. This was not the case among patients with non-atheromatous cerebral infarction $(\mathrm{NACl})$, whose lipids profile was found to be similar to that of healthy individuals.

Our results contribute new evidence in the quest for an answer to the long-standing question: Is there an association between blood lipids levels and occurrence of stroke? According to our findings, the answer is that high levels of total cholesterol, LDL, and triglycerides are associated with the occurrence of $\mathrm{ACl}$, while low levels of total cholesterol and high levels of triglycerides are linked to occurrence of cerebral hemorrhage.

These preliminary results may shed light on the scientific debate, since they point to the need to stratify cerebral vascular accidents based on their type (ischemic or hemorrhagic) and on their etiopathogenesis, in order to determine the real association between lipid alterations and occurrence of these neurological events. For the same reason, this study may also help guide future trials attempting to relate lipid alterations with occurrence of vascular events.

\section{CONCLUSIONS}

The type (ischemic or hemorrhagic) and etiopathogenesis of stroke must be considered when studying the association between its occurrence and blood lipids levels. High levels of total cholesterol, LDL, and triglycerides are associated with occurrence of atheromatous cerebral infarction, while low levels of total cholesterol and high levels of triglycerides are linked with occurrence of cerebral hemorrhage. Th-

\section{REFERENCES}

1. Fruchart JC, Nierman MC, Stroes ES, Kastelein JJ, Duriez P. New risk factors for atherosclerosis and patient risk assessment. Circulation. 2004;109(23 Sup 1):III15-9.

2. Prospective Studies Collaboration. Cholesterol, diastolic blood pressure, and stroke: 13,000 strokes in 450,000 people in 45 prospective cohorts. Lancet. 1995;346:1647-53.

3. Iso H, Jacobs DR, Wentworth D, Neaton JD, Cohen JD for the MRFIT Research Group. Serum cholesterol levels and six-year mortality from stroke in 350,977 men screened for the multiple risk factor intervention trial. $\mathrm{N}$ Engl J Med. 1989;320:904-10.

4. Amarenco P, Lavallee P, Touboul JP. Stroke prevention, blood cholesterol, and statins. Lancet Neurol. 2004;3:271-8.

5. The Stroke Prevention by Aggressive Reduction in Cholesterol Levels (SPARCL) Investigators. High-dose atorvastatin after stroke or transient ischemic attack. N Engl J Med. 2006;355:54959.

6. Davignon J. Beneficial cardiovascular pleiotropic effects of statins. Circulation. 2004;109(23 Suppl 1):III39-43.

7. Zhou J, Zhang M, Li XM. Comparative study of serum lipids and serum lipoprotein spectrum in patients with cerebrovascular diseases. Di Yi Jun Yi Da Xue Xue Bao. 2003;23(3):262-4

8. López-Virella MF. Comparison of 3 methods of selective isolation for HDL determination. Clin Chem. 1977;23:882.
9. Díez-Tejedor E, Del Brutto O, Álvarez-Sabín J, Muñoz M, Abiusi G. Clasificación de las enfermedades cerebrovasculares. Sociedad Iberoamericana de Enfermedades Cerebrovasculares. Rev Neurol. 2001;33(5):455-64.

10. Informática Médica. Bioestadística Tomo II. CECAM. La Habana: Editorial Ciencias Médicas, 2004.

11. González S, Fernández $\mathrm{O}$, González A, Fernández R, Molina L, Valdés V. Las alteraciones lipídicas en el infarto cerebral. Rev Inv Biomed. 2001;21(3):149-154.

12. $X u H$, Yang $Q$, Tang $B$. Studies on stroke and blood lipid level. Zhonghua Yu Fang Yi Xue Za Zhi. 1998;32(6):366-8.

13. Peng $D$, Zhao S. Serum lipids, lipoprotein and stroke. Hunan Yi Ke Da Xue Xue Bao. 1999;24(2):167-70

14. Liu XN, Gao Y, Ye J, Wang DW, Liao YH, Ma AQ, et al. Association of small, dense low density lipoprotein with stroke. Zhonghua Yi Xue Za Zhi. 2003;83(22):1939-42

15. Denti L, Cecchetti A, Annoni V, Merli MF, Ablondi $\mathrm{F}$, Valenti $\mathrm{G}$. The role of lipid profile in determining the risk of ischemic stroke in the elderly: a case-control study. Arch Gerontol Geriatr. 2003;37(1):51-62

16. Horenstein RB, Smith DE, Mosca L. Cholesterol predicts stroke mortality in the Women's Pooling Project. Stroke. 2002;33(7):1863-8.

17. Amarenco $P$, Labreuche J, Lavallee $P$, Touboul PJ. Statins in Stroke Prevention and Carotid Ath- erosclerosis. Systematic Review and Up-to-Date Meta-Analysis. Stroke. 2004;35(12):2902-9.

18. Gresser U, Gathof BS. Atorvastatin: Gold standard for prophylaxis of myocardial ischemia and stroke - comparison of the clinical benefit of statins on the basis of randomized controlled endpoint studies. Eur J Med Res. 2004;9(1):1-17.

19. Sasaki J, Arakawa K, Iwashita M, Matsushita $Y$ Kono S. Kyushu Lipid Intervention Study (KLIS) Group. Reduction in serum total cholesterol and risks of coronary events and cerebral infarction in Japanese men: the Kyushu Lipid Intervention Study. Jpn Circ J. 2003;67(6):473-8.

20. Wierzbicki AS, Mikhailidis DP, Wray R, Schacter M, Cramb R, Simpson WG, et al. Statin-fibrate combination: therapy for hyperlipidemia: a review. Curr Med Res Opin. 2003;19(3):155-68.

21. Tanne D, Yaari S, Goldbourt U. High-density lipoprotein cholesterol and risk of ischemic stroke mortality. A 21-year follow-up of 8,586 men from the Israeli Ischemic Heart Disease Study. Stroke. 1997;28(1):83-7.

22. Soyama $Y$, Miura $K$, Morikawa $Y$, Nishijo M, Nakanishi Y, Naruse Y, et al. Oyabe Study. Highdensity lipoprotein cholesterol and risk of stroke in Japanese men and women: the Oyabe Study. Stroke. 2003;34(4):863-8.

23. Curb JD, Abbott RD, Rodriguez BL, Masaki $\mathrm{KH}$, Chen R, Popper JS, et al. High density lipoprotein cholesterol and the risk of stroke in elderly men: the Honolulu Heart Program. Am J Epidemiol. 2004;160(2):150-7. 
24. Morales A, Morera-Guitart J, Bautista-Prados J Clar C, Herruzo E, Mas G, et al. Diagnóstico etiológico del infarto cerebral en el hospital comarcal. Rev Neurol. 2003;36(5):405-11.

25. González S, Fernández O, González A, Fernández R, Valdés M. Papel de los lípidos sanguíneos en las distintas etiologías del infarto cerebral. Rev Neurol. 2003;36(7):625-8.

26. Bowman TS, Sesso HD, Ma J, Kurth T, Kase Cl, Stampfer MJ, et al. Cholesterol and the risk of ischemic stroke. Stroke. 2003;34(12):2930-4.

27. Laloux P, Galanti L, Jamart J. Lipids in ischemic stroke subtypes. Acta Neurol Belg. 2004:104(1):13-9.

28. Pines A, Bornstein NM, Shapira I. Menopause and ischemic stroke: basic clinical and epidemiological considerations. The role of hormone replacement. Hum Reprod Update. 2002;8(2):161 168.

29. Okumura K, Iseki K, Wakugami K, Kimura Y, Muratani $\mathrm{H}$, Ikemiya $\mathrm{Y}$, et al. Low serum cholestero as a risk factor for hemorrhagic stroke in men: a community-based mass screening in Okinawa, Japan. Jpn Circ J. 1999;63(1):53-8.

30. Iribarren C, Jacobs DR, Sadler M, Claxton AJ, Sidney S. Low total serum cholesterol and intracerebral hemorrhagic stroke: is the as sociation confined to elderly men? The Kaise
Permanente Medical Care Program. Stroke. 1996;27(11):1993-8.

31. Amarenco P, Steg PG. The paradox of cholestero and stroke. Lancet. 2007;370:1803-1804.

\section{THE AUTHORS}

Sergio González García (Corresponding Author: sergiogg@infomed.sld.cu) biochemist, assistant researcher, assistant professor, Institute of Neurology and Neurosurgery, Havana, Cuba.

Otman Fernández Concepción, specialist in neurology, associate researcher, associate professor, Institute of Neurology and Neurosurgery, Havana, Cuba.

Rebeca Fernández Carriera, biochemist, associate researcher, associate professor, Institute of Neurology and Neurosurgery, Havana, Cuba.
Caridad Menéndez Saínz, biochemist, associate researcher, associate professor, Institute of Neurology and Neurosurgery, Havana, Cuba.

Julia Maza, head of the Clinical Laboratory, assistant researcher, associate professor, Institute of Neurology and Neurosurgery, Havana, Cuba.

Alina González-Quevedo Monteagudo, deputy director of research, full professor and researcher, Institute of Neurology and Neurosurgery, Havana, Cuba.

Miguel Ángel Buergo Zuaznábar, specialist in neurology, associate professor, Institute of Neurology and Neurosurgery, Havana, Cuba.

Submitted: October 24, 2007

Approved for publication: February 20, 2008

\section{Erratum}

Page 28, full paragraph 8 , second sentence should read: "Serum was stored at $-20^{\circ} \mathrm{C}$ for no longer than 20 days."

\section{5th International Symposium:} Definition of Death Network

Plaza Américas Convention Center Varadero, Cuba

May 20-23, 2008

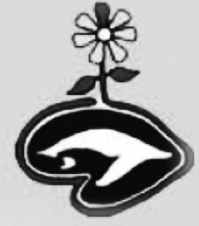

Contact: Calixto Machado, MD, PhD E-mail: braind@infomed.sld.cu http://www.changesurfer.com/BD/index.htm Organized by: The International Association of Bioethics
- Conceptual approach to human death

- End-of-life dilemmas

- Coma, persistent vegetative state (PVS), minimally conscious state (MCS), and coma

- Legal considerations on brain death and related states

- Neuroimaging and neurphysiological techniques for assessing coma, PVS and MCS

- Neurorehabilitation of PVS and MCS

- New trends in cerebral cardio-pulmonary-cerebral resuscitation 